\title{
A Design of Rectangular Patch Antenna with Fractal Slots for Multiband Applications
}

\author{
Parveen Luthra \\ M.Tech Scholar \\ Electronics \& communication \\ GIMET, Amritsar
}

\author{
Kiranbir Kaur \\ Assistant Professor \\ Electronics \& communication \\ GIMET, Amritsar
}

\begin{abstract}
The design of rectangular patch antenna with fractal slots is presented in this paper. For designing the antenna FR4 epoxy substrate with thickness $1.6 \mathrm{~mm}$ and relative permittivity of 4.4 is used as substrate. The resonant frequency used for designing the proposed antenna is $2 \mathrm{GHz}$. Three iteration of proposed antenna is designed and simulated by using HFSS V13 software and different parameters of antenna such as return loss, gain VSWR and radiation pattern are analyzed and observed. The simulated result shows that the designed antenna works on eight different resonant frequencies where the return loss is below $-10 \mathrm{~dB}$ with VSWR less than 2 which is the desired condition for the antenna to work efficiently for practical applications. The designed antenna can be used for different wireless applications in frequency bands such as Lband, S-band, C-band and X-band.
\end{abstract}

\section{Keywords}

Fractal slots, VSWR, HFSS multiband.

\section{INTRODUCTION}

In the world of wireless communication there is a need of multi-functional and multiband antennas. So according to the need the latest research in antenna technology the fractal geometry of antenna took a vital role [2]. The two properties of fractal geometry such as self-similarity and space-filling which makes the antenna to work on multi frequency bands [6]. B. Mandelbort defined the fractal geometry based on iteration process in 1975. There are many different shapes of fractal antenna have been designed so far such as sierpinski carpet, sierpinski gasket, Koch-curve etc [5]. Fractal is a geometry shape that is sub divided into different parts and the each part is a copy of complete antenna shape at varying dimensions [3]. Use of fractal geometry improves the features and performance of antenna. So, the fractal antenna used in many wireless applications like WLAN bands are $2.4 \mathrm{GHz}$, $5.2 \mathrm{GHz}$ and $5.8 \mathrm{GHz}$, Wi-MAX bands are $2.5 \mathrm{GHz}, 3.5 \mathrm{GHz}$ and $5.8 \mathrm{GHz}$, Bluetooth at $2.4 \mathrm{GHz}$ etc [4].

In this paper the rectangular patch antenna with fractal slots for multiband applications is designed. Simulated results and the detailed design concept are presented to demonstrate the performance of a proposed antenna.

\section{ANTENNA DESIGN}

There are many parameters has been taken in to consideration while designing patch antennas such as resonant frequencies, substrate thickness, length of patch, width of patch etc. These dimensions are calculated by using the rectangular patch design equations (1) to (5) as shown below. In this design the FR4 epoxy substrate is used as a substrate material with dielectric constant 4.4 , thickness $1.6 \mathrm{~mm}$ and the resonant frequency taken as $2 \mathrm{GHz}$.

Calculation of Width (W)

The width of the patch element $(\mathrm{W})$ is given by [1]

$$
w=\frac{C}{2 f o \sqrt{\frac{\varepsilon_{r}+1}{2}}}
$$

Calculation of Effective dielectric constant $\left(\varepsilon_{\text {reff }}\right)$ [1]

$\varepsilon_{\text {reff }}=\frac{\varepsilon_{r}+1}{2}+\frac{\varepsilon_{r}-1}{2}\left[1+12 \frac{h}{w}\right]^{\frac{1}{2}}$

Calculation of Effective length [1]

$L_{e f f}=\frac{C}{2 f o \sqrt{\varepsilon_{\text {reff }}}}$

Calculation of the length extension [1]

$\Delta L=0.412 h \frac{\left(\varepsilon_{\text {reff }}+0.3\right)\left(\frac{w}{h}+0.264\right)}{\left(\varepsilon_{\text {reff }}-0.258\right)\left(\frac{w}{h}+0.8\right)}$

The actual length $(\mathrm{L})$ of patch [1]

$L=L_{e f f}+2 \Delta L$

Where,

$c=$ Velocity of light in free space.

$h=$ Substrate height.

$\varepsilon_{r}=$ Relative permittivity of the substrate.

The length and width of rectangular patch antenna comes to be $35.44 \mathrm{~mm}$ and $45.64 \mathrm{~mm}$ respectively.

In this section three iterations of rectangular patch antenna are designed. The $0^{\text {th }}$ iteration of the proposed antenna is designed by taking the length and width as $35.44 \mathrm{~mm}$ and 45.64 respectively and the design is modified by cutting the four rectangular slots of length $2 \mathrm{~mm}$ and width $2.5 \mathrm{~mm}$ at the edges of rectangular patch. The structural details of proposed antenna are depicted in Figure 1 and its parametric values are shown in Table 1. 


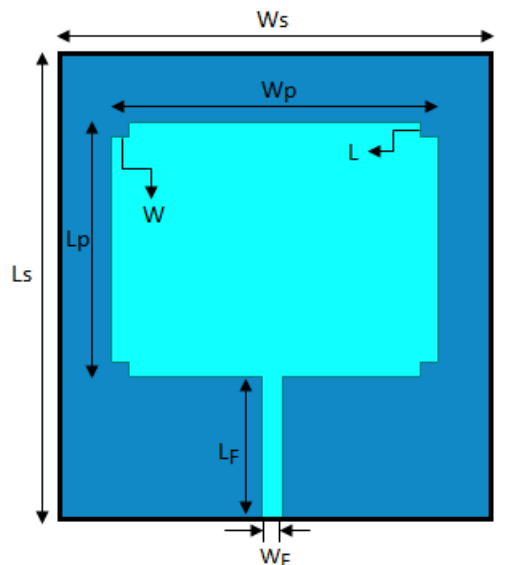

Figure 1: Proposed antenna $0^{\text {th }}$ iteration

Table 1: Parametric values of $0^{\text {th }}$ iteration of proposed antenna

\begin{tabular}{|c|c|c|c|}
\hline S. No. & Parameters & Description & Values \\
\hline 1. & Ls & Length of substrate & $65 \mathrm{~mm}$ \\
\hline 2. & Ws & Width of substrate & $60 \mathrm{~mm}$ \\
\hline 3. & Lp & Length of patch & $35.44 \mathrm{~mm}$ \\
\hline 4. & $\mathrm{Wp}$ & Width of patch & $45.64 \mathrm{~mm}$ \\
\hline 5. & $\mathrm{~L}_{\mathrm{F}}$ & Length of feed line & $19.78 \mathrm{~mm}$ \\
\hline 6. & $\mathrm{~W}_{\mathrm{F}}$ & Width of feed line & $3 \mathrm{~mm}$ \\
\hline 7. & $\mathrm{~L}$ & Length of slots & $2 \mathrm{~mm}$ \\
\hline 8. & W & Width of slots & $2.5 \mathrm{~mm}$ \\
\hline
\end{tabular}

The $1^{\text {st }}$ iteration of proposed antenna has been designed by taking all the dimensions same as the $0^{\text {th }}$ iteration but in $1^{\text {st }}$ iteration rectangular slot is extracted from the centre of rectangular patch. The length and width of the rectangular slot is $10 \mathrm{~mm}$ and $12 \mathrm{~mm}$ respectively. The simulated structure of $1^{\text {st }}$ iteration is shown in Figure 2.

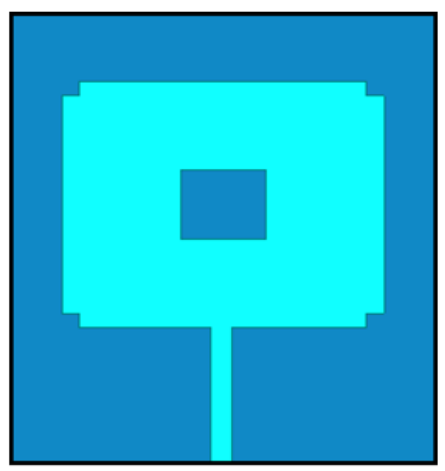

Figure 2: proposed antenna $1^{\text {st }}$ iteration

The $2^{\text {nd }}$ iteration of proposed antenna has been designed by taking the $1^{\text {st }}$ iteration as a base geometry and extracting the four rectangular slots at the sides of rectangular slot that has been extracted in the $1^{\text {st }}$ iteration of proposed antenna. The length and width of the four slots are $1 / 2^{\text {nd }}$ the length and width of rectangular slot extracted in previous geometry. So the length and width of four slots comes to be $5 \mathrm{~mm}$ and $6 \mathrm{~mm}$ respectively. The simulated structure of $2^{\text {nd }}$ iteration of proposed antenna is shown in Figure 3.

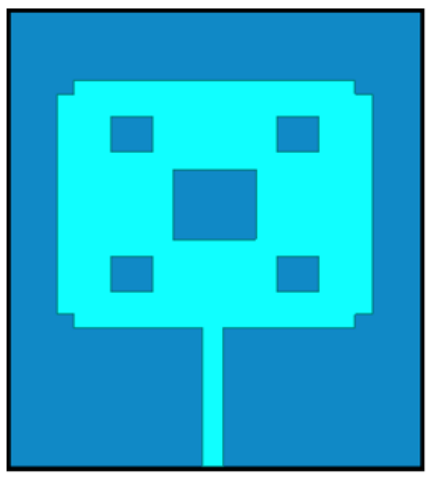

Figure 3: Proposed antenna $2^{\text {nd }}$ iteration

\section{RESULT AND DISCUSSIONS}

\subsection{Return loss and VSWR}

Return loss is an important parameter of antenna. It is the difference between forward and reflected power in $\mathrm{dB}$. The return loss is the ratio of reflected power over transmitted power. The acceptable value of return loss is below $-10 \mathrm{~dB}$ for the antenna to work efficiently. The return $\mathrm{v} / \mathrm{s}$ frequency curve of $0^{\text {th }}, 1^{\text {st }}$ and $2^{\text {nd }}$ iteration are shown in Figure 4, 5 and 6 respectively. VSWR is Voltage Standing Wave Ratio it shows the impedance mismatch between the feeding system and antenna. Higher VSWR means higher mismatch. The acceptable value of VSWR is less than 2 and it is a dimension less quantity. The VSWR v/s frequency curve of $0^{\text {th }}, 1^{\text {st }}$ and $2^{\text {nd }}$ iteration of proposed antenna are shown in Figure 7, 8 and 9 respectively.

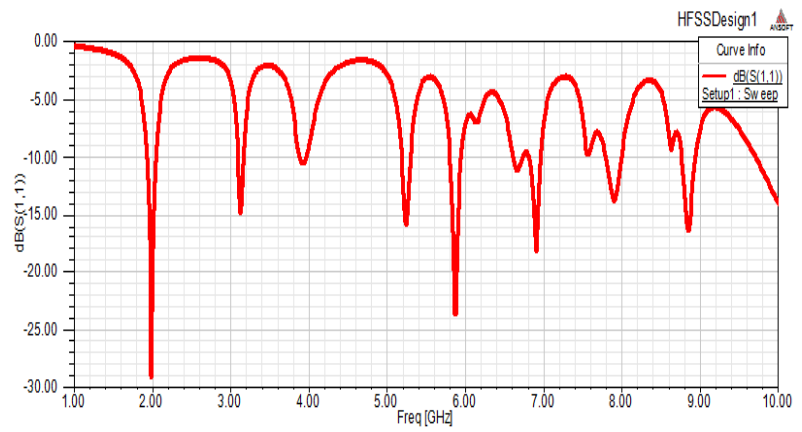

Figure 4: Return loss v/s frequency curve of $0^{\text {th }}$ iteration of proposed antenna

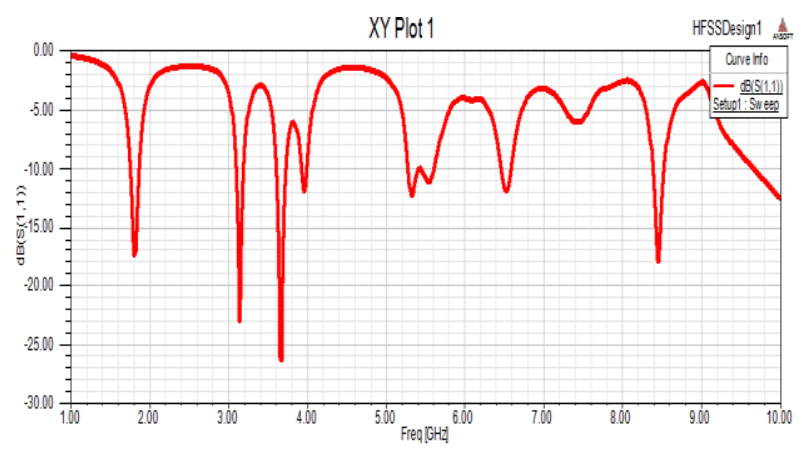

Figure 5: Return loss v/s frequency curve of $1^{\text {st }}$ iteration of proposed antenna 


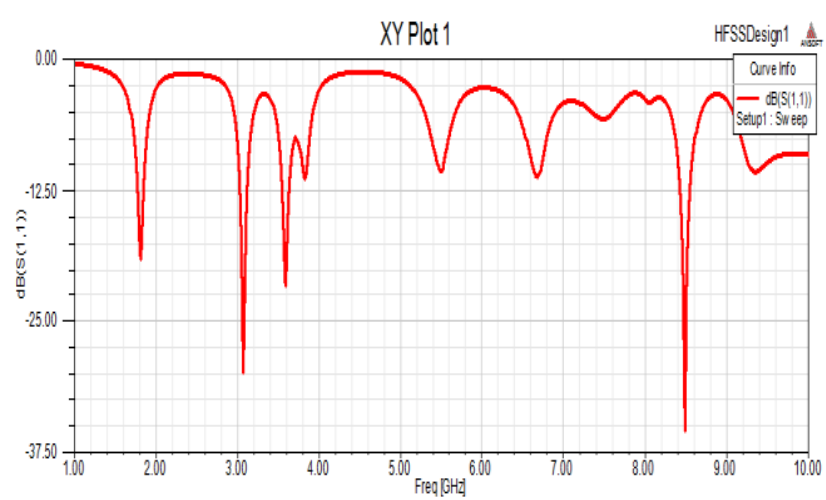

Figure 6: Return loss v/s frequency curve of $2^{\text {nd }}$ iteration of proposed antenna

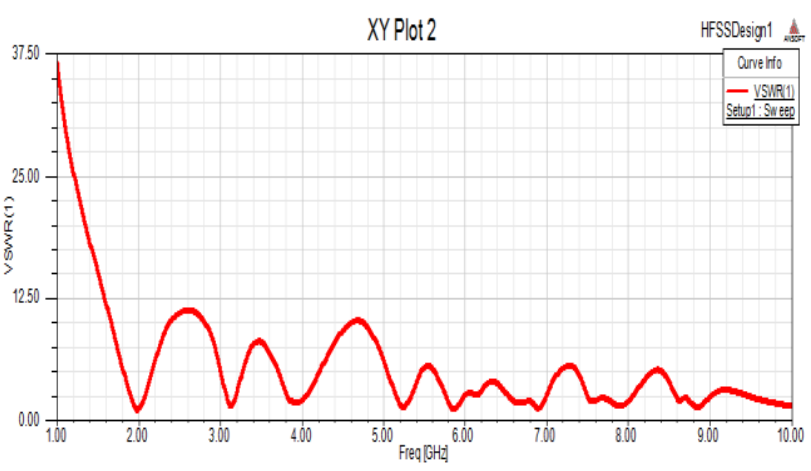

Figure 7: VSWR v/s frequency curve of $0^{\text {th }}$ iteration of proposed antenna

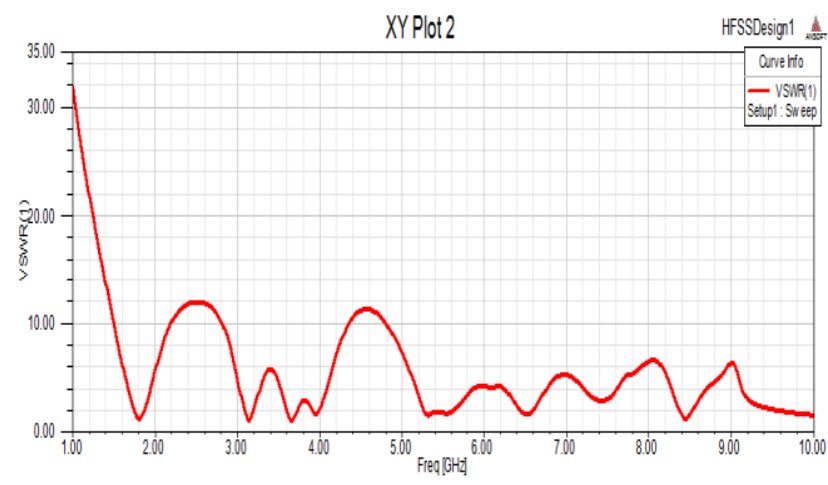

Figure 8: VSWR v/s frequency curve of $1^{\text {st }}$ iteration of proposed antenna

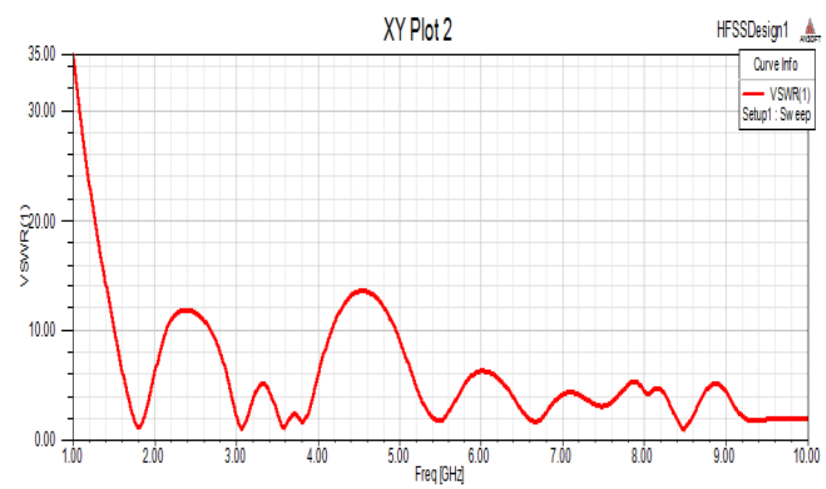

Figure 9: VSWR v/s frequency curve of $2^{\text {nd }}$ iteration of proposed antenna

\subsection{Gain And Radiation Pattern}

Gain shows the directional capability and efficiency of antenna. The acceptable value of antenna gain is $3 \mathrm{~dB}$ or more. The 3-D gain plot of proposed antenna for $0^{\text {th }}, 1^{\text {st }}$ and $2^{\text {nd }}$ iteration is shown in Figure 10, 11 and 12. Radiation pattern shows the directivity nature in far field region for both azimuth and elevation plane. The radiation patterns of proposed antenna of $0^{\text {th }}, 1^{\text {st }}$ and $2^{\text {nd }}$ iteration for both azimuth and elevation plane are shown in Figure 13, 14 and 15 respectively.

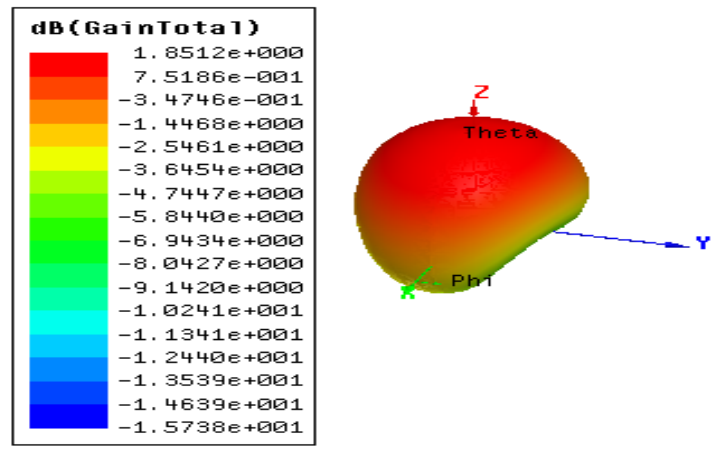

Figure 10: 3D gain plot of $0^{\text {th }}$ iteration of proposed antenna
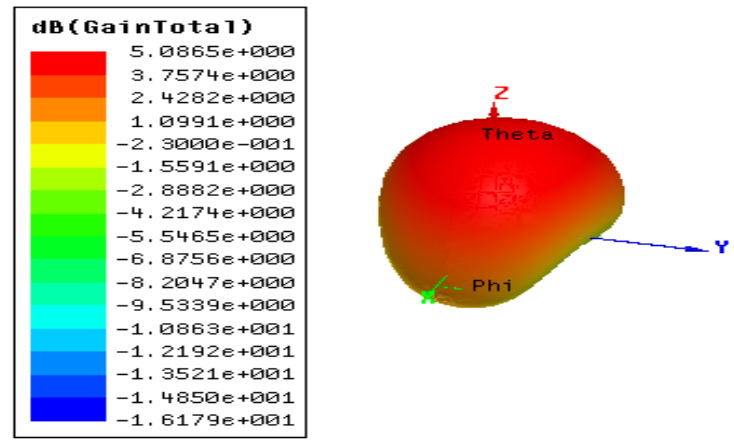

Figure 11: 3D gain plot of $1^{\text {st }}$ iteration of proposed antenna

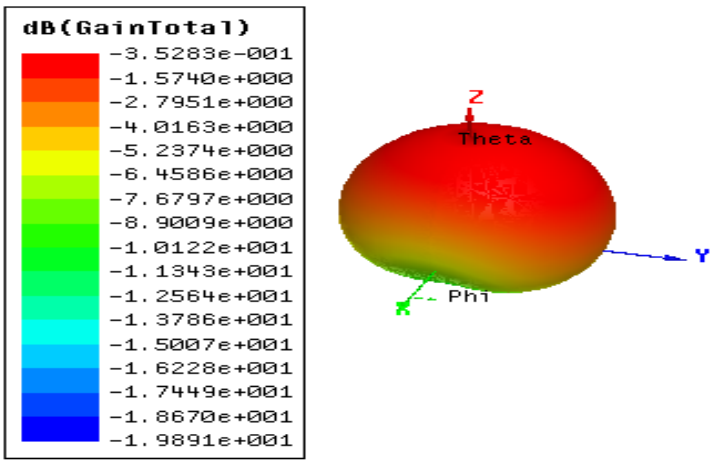

Figure 12: 3D gain plot of $2^{\text {nd }}$ iteration of proposed antenna 


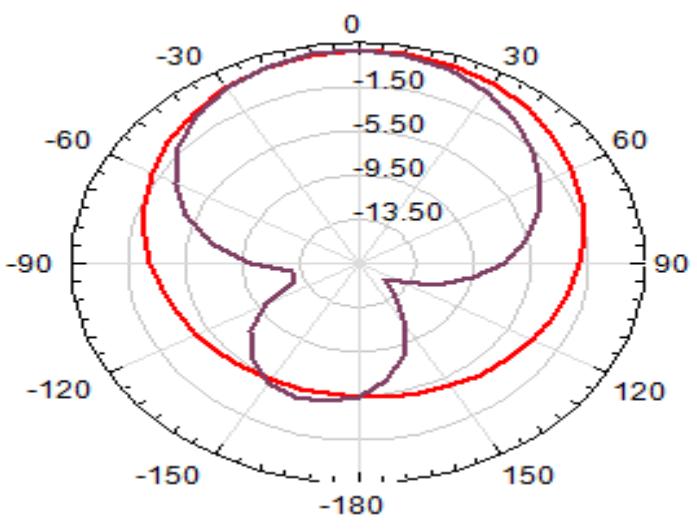

Figure 13: 2D Radiation Pattern of $0^{\text {th }}$ iteration of proposed antenna

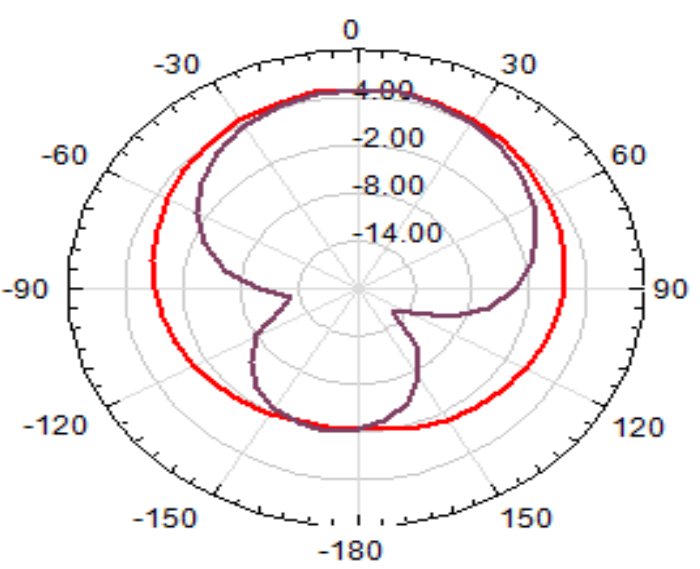

Figure 14: 2D radiation Pattern of $1^{\text {st }}$ iteration of proposed antenna

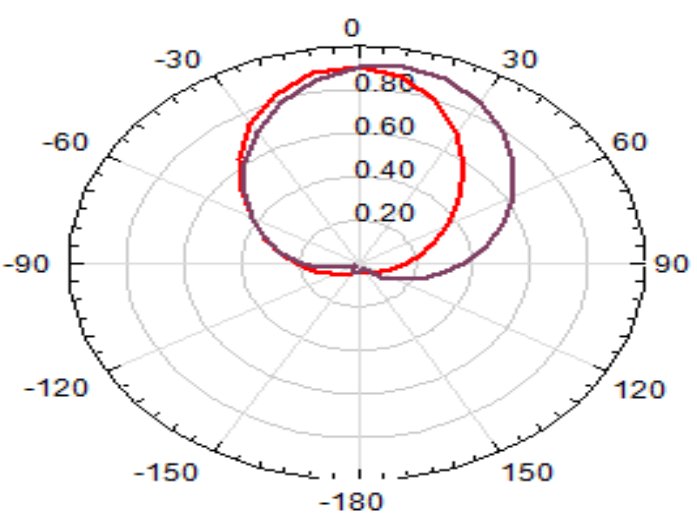

Figure 15: 2D radiation Pattern of $2^{\text {nd }}$ iteration of proposed antenna

The 3D gain plot of $2^{\text {nd }}$ iteration of proposed antenna shows the negative value of gain which is not acceptable value of the gain for antenna to work for practical applications. So the gain is increased by changing the dimensions in $2^{\text {nd }}$ iteration of proposed antenna design. By changing the length and width of the slots extracted at the edges from $\mathrm{L}=2 \mathrm{~mm}$ and $\mathrm{W}=2.5 \mathrm{~mm}$ to $\mathrm{L}=2 \mathrm{~mm}$ and $\mathrm{W}=2 \mathrm{~mm}$. The gain of antenna becomes positive $(4.51 \mathrm{~dB})$ and also at acceptable level. The simulated results of gain and radiation pattern after modification in the geometry of 2 nd iteration of proposed antenna are shown in Figure 16 and 17 respectively.
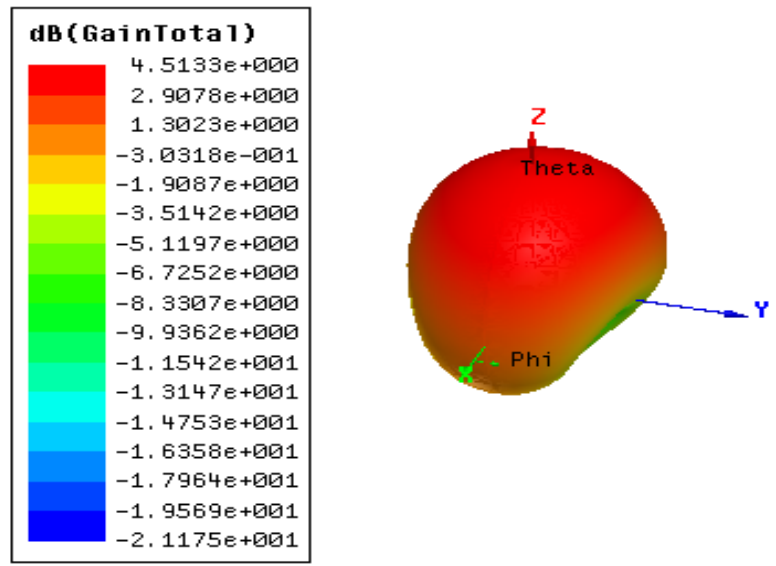

Figure 16: 3D gain plot of $2^{\text {nd }}$ iteration of proposed antenna with $L=2 \mathrm{~mm}$ and $\mathrm{W}=\mathbf{2} \mathrm{mm}$

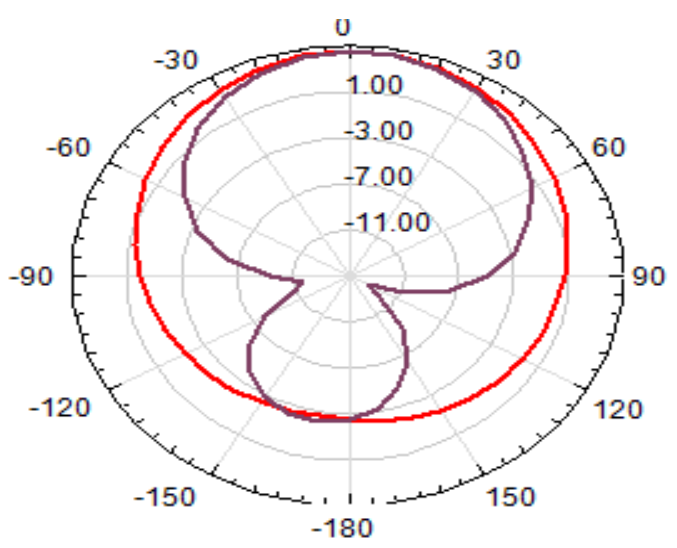

Figure 17: 2D Radiation pattern of $2^{\text {nd }}$ iteration of proposed antenna with $\mathrm{L}=\mathbf{2} \mathrm{mm}$ and $\mathrm{W}=\mathbf{2} \mathrm{mm}$

Table 2: Comparison of simulated results of $0^{\text {th }}, 1^{\text {st }}$ and $2^{\text {nd }}$ iteration of rectangular slot antenna

\begin{tabular}{|c|c|c|c|}
\hline Iteration & $\begin{array}{c}\text { Resonant } \\
\text { Frequency } \\
\text { in GHz }\end{array}$ & $\begin{array}{c}\text { Return loss in } \\
\mathrm{dB}\end{array}$ & VSWR \\
\hline $0^{\text {th }}$ iteration & $1.99,3.12$, & $-29.00,-14.75,-$ & $1.07,1.44$, \\
& $3.93,5.24$, & $10.49,-15.78,-$ & 1.85, \\
& $5.86,6.90$, & $23.58,-18.19,-$ & $1.38,1.14$, \\
& 7.90 and & 13.79 and -16.32 & $1.28,1.51$ \\
& 5.85 & & and 1.36 \\
\hline $1^{\text {st }}$ iteration & $1.82,3.14$, & $-17.05,-23.03,-$ & $1.32,1.15$, \\
& $3.66,3.96$, & $26.23,-11.96,-$ & $1.10,1.67$, \\
& $5.31,5.55$, & $12.29,-11.18,-$ & $1.64,1.76$, \\
& 6.53 and & 11.88 and -17.87 & 1.68 and \\
& 8.44 & & 1.29 \\
\hline $2^{\text {nd }}$ iteration & $1.81,3.07$, & $-18.97,-29.92,-$ & $1.25,1.06$, \\
$(\mathrm{L}=2 \mathrm{~mm}$ & $3.59,3.81$, & $21.60,-11.42,-$ & $1.18,1.73$, \\
and & $5.48,6.67$, & $10.62,-11.21,-$ & $1.83,1.75$, \\
$\mathrm{W}=2.5 \mathrm{~mm})$ & 8.49 and & 35.32 and -10.74 & 1.03 and \\
& 9.34 & & 1.81 \\
\hline $2^{\text {nd }}$ iteration & $1.77,3.03$, & $-13.17,-29.96,-$ & $1.58,1.06$, \\
$(\mathrm{L}=2 \mathrm{~mm}$ & $3.53,3.74$, & $30.50,-16.28,-$ & $1.06,1.43$, \\
and & $6.46,9.16$ & $18.47,-26.69$ & $1.29,1.11$ \\
$\mathrm{~W}=2 \mathrm{~mm})$ & and 10.00 & and -13.65 & and 1.52 \\
\hline
\end{tabular}




\section{CONCLUSIONS}

The paper presents the design of rectangular patch antenna with fractal slots for multiband applications. The three iterations of proposed antenna have been designed. Antenna parameters such as return loss, VSWR, gain and radiation patterns are observed and analyzed. On analyzing the simulated results it shows that the designed antenna works on eight resonant frequencies where the return losses are below $10 \mathrm{~dB}$ for all frequency bands and the overall gain is also at acceptable level. So the designed antenna can be used for various wireless frequency bands of different applications.

\section{REFERENCES}

[1] C. A. Balanis, "Antenna theory: Analysis and Design, $3^{\text {rd }}$ edition, Wiley, 2005.

[2] P. S. R. Chowdary, A. M. Prasad and P. M. Rao, "Design of Modified Sierpinski Antenna for WLAN Applications," International Conference on Electronics and Communication System (ICECS), 2014.
[3] R. Choudhary, S. Yadav, P. Jain and M. M. Sharma, "Full Composite Fractal Antenna with Dual Band used for Wireless Applications," International Conference on Advances in Computing, Communications and Informatics (ICACCI), pp. 2517-2520, 2014.

[4] S. Yadav, R. Choudhary, U. Soni, A. Dadhich and M. M. Sharma, "A Dual Band Star Fractal Antenna with Slot for Wireless Applications," International Conference on Signal Propagation and Computer Technology (ICSPCT), IEEE, pp. 738-740, 2014.

[5] S. Yadav, P. Jain and R. Choudhary, "A Novel approach of triangular circular fractal antenna," International Conference on Advances in Computing, Communications and Informatics (ICACCI), IEEE, pp. 708-711, 2014.

[6] S. Kundalia, V. Unadkat and S. Dwivedi, "Comparative analysis of fractal based nested triangular microstrip antnna," IEEE, 2014. 